\title{
Carbon monoxide diffusing capacity and the complexity of diagnosis in pulmonary arterial hypertension
}

\author{
Rogerio Souza', Caio J.C. Fernandes ${ }^{1}$ and Marius M. Hoeper ${ }^{2}$
}

\begin{abstract}
Affiliations: ${ }^{1}$ Pulmonary Dept, Heart Institute, University of São Paulo Medical School, São Paulo, Brazil. ${ }^{2}$ Dept of Respiratory Medicine and Centre for Lung Research (DLZ/BREATH), Hannover Medical School, Hannover, Germany.
\end{abstract}

Correspondence: R. Souza, Pulmonary Dept, Heart Institute, University of São Paulo Medical School, Av. Dr. Eneas de Carvalho Aguiar 44, São Paulo, 05403-000, Brazil. E-mail: rogerio.souzadincor.usp.br

-

@ERSpublications

We should be aware that low DLCO in a patient presenting with PAH may signal another disease and a dismal prognosis http://ow.ly/tvK6w

The increased interest in pulmonary arterial hypertension (PAH) witnessed during the last decades has dramatically changed our comprehension of the disease and its management, resulting in better functional capacity and haemodynamic profiles, and increased survival $[1,2]$. The discovery of different pathophysiological pathways associated with PAH progression has allowed the development of targeted therapies that were responsible for such improvements [3].

Recently, more attention has been paid to the epidemiology and distinct phenotypes of PAH, not least by publication of several registries expanding our knowledge on the clinical and demographic characteristics of PAH patients [4-9] as well as on the burden that previously unrecognised forms of PAH might represent [10]. The pivotal study conducted by the US National Institutes of Health in the 1980s [11, 12] provided invaluable information about the natural course of PAH. The patients in that cohort were predominantly young females (mean age of 36 years) presenting with what was then called primary pulmonary hypertension, i.e. idiopathic, familial or appetite suppressant-associated PAH. The presence of comorbidities did not represent a significant issue at that time, and patients seemed to present with pure vascular disease and few comorbidities. Recent registries have shown a considerable shift in this scenario [4-9]. Particularly in the western world, the majority of PAH patients are now diagnosed at older age (50-60 years or even older) with a significant increase in comorbidities not necessarily, but possibly, associated with the development of pulmonary hypertension. The UK and Ireland registry recently described a subgroup of newly diagnosed PAH patients $>50$ years of age with increased prevalence of obesity, systemic hypertension, diabetes and ischaemic heart disease, presenting with a worse prognosis, despite a seemingly better haemodynamic profile at baseline [6]. Nonetheless, some of these comorbidities may also cause pulmonary hypertension, hence increasing the complexity in diagnosing PAH [13]. Most of the current classification system for pulmonary hypertension is based on the baseline clinical condition and haemodynamic profile of the patient [14]. In this sense, coexistence of multiple clinical conditions such as mild emphysema or pulmonary fibrosis, or even mild heart failure with preserved ejection fraction, which is commonly seen in the elderly, might complicate the appropriate diagnosis. Thus, we need better diagnostic markers to define and distinguish the various phenotypes of pulmonary vascular disease.

Diffusing capacity of the lung for carbon monoxide (DLCO) is one of these potential markers thanks to its characteristic of reflecting alveolar and microvascular integrity [15]. For many years, a low DLCO has been associated with the development of PAH in patients with systemic sclerosis [16]. Other conditions where DLCO is

Received: Feb 042014 | Accepted: Feb 062014

Conflict of interest: None declared.

Copyright @ERS 2014 
typically reduced include pulmonary veno-occlusive disease and pulmonary hypertension associated with emphysema, interstitial lung disease or combined pulmonary fibrosis and emphysema [17, 18]. Clinical experience suggests that all these forms of pulmonary hypertension respond poorly to PAH therapy and carry a particularly poor prognosis. Of note, DLCO is usually normal or only mildly reduced in idiopathic PAH (IPAH) but it has been suggested that IPAH patients with severely reduced DLCO present worse survival [19]. Thus, it is possible that a low DLCO signals a particular phenotype of pulmonary vascular disease, presumably associated with a loss of functional pulmonary capillaries.

A recent study, published in European Respiratory Journal (ERJ), revisited the significance of severe reductions in DLCO in patients with IPAH [20]. At first, univariate analysis demonstrated that low DLCO $(<45 \%$ predicted) was associated with a poor survival. However, baseline demographics of patients presenting with low DLCO were significantly different from those of patients with higher DLCO. Severe reduction in DLCO was associated with male sex, older age, greater tobacco exposure and a higher prevalence of concomitant coronary disease. The independent prognostic value of DLCO was lost in the multivariate analysis but these findings still suggest that patients with a very low DLCO suffer from a unique variant of $\mathrm{PAH}$.

In this issue of ERJ, the same group, now in association with the French National Reference Centre, further extend their evaluation of DLCO in PAH in patients carrying mutations in the bone morphogenetic protein receptor type II gene (BMPR2) [21]. Although BMPR2 mutation carriers presented with a worse haemodynamic profile in terms of cardiac index and pulmonary vascular resistance, DLCO tended to be higher than in noncarriers. Limiting the analysis only to the nonsmoking patients did not alter these results.

In aggregate, these findings support the hypothesis that there may be distinct pulmonary vasculopathies that eventually lead to PAH. The authors speculate on the presence of a potentially different pulmonary vascular remodelling process in BMPR2 mutation carriers. Alternatively, DLCO may be higher in BMPR2 carriers because these patients might represent a more pure pulmonary vascular disease, as compared with noncarriers who might present with occult parenchymal lung disease or veno-occlusive variants. The authors followed current diagnostic algorithms in order to exclude these conditions, but it is clear that our diagnostic tools are not yet sufficient to fully understand the pathological and functional changes occurring at the level of the pulmonary microvasculature $[13,22]$.

In conclusion, TRIP et al. [21] are to be commended for reminding us that DLCO measurements are useful in patients with pulmonary disease. Even if we do not yet comprehend all the details, we should be aware that a low DLCO in a patient presenting with what looks like PAH may signal the presence of another disease and, unfortunately, often a dismal prognosis.

\section{References}

1 Galie N, Manes A, Negro L, et al. A meta-analysis of randomized controlled trials in pulmonary arterial hypertension. Eur Heart J 2009; 30: 394-403.

2 Souza R, Jardim C, Humbert M. Idiopathic pulmonary arterial hypertension. Semin Respir Crit Care Med 2013; 34: 560-567.

3 Galie N, Corris PA, Frost A, et al. Updated treatment algorithm of pulmonary arterial hypertension. J Am Coll Cardiol 2013; 62: Suppl., D60-D72.

4 Badesch DB, Raskob GE, Elliott CG, et al. Pulmonary arterial hypertension: baseline characteristics from the REVEAL Registry. Chest 2010; 137: 376-387.

5 Humbert M, Sitbon O, Chaouat A, et al. Pulmonary arterial hypertension in France: results from a national registry. Am J Respir Crit Care Med 2006; 173: 1023-1030.

6 Ling Y, Johnson MK, Kiely DG, et al. Changing demographics, epidemiology, and survival of incident pulmonary arterial hypertension: results from the pulmonary hypertension registry of the United Kingdom and Ireland. Am J Respir Crit Care Med 2012; 186: 790-796.

7 Thenappan T, Shah SJ, Rich S, et al. A USA-based registry for pulmonary arterial hypertension: 1982-2006. Eur Respir J 2007; 30: 1103-1110.

8 Jing ZC, Xu XQ, Han ZY, et al. Registry and survival study in Chinese patients with idiopathic and familial pulmonary arterial hypertension. Chest 2007; 132: 373-379.

9 Hoeper MM, Huscher D, Ghofrani HA, et al. Elderly patients diagnosed with idiopathic pulmonary arterial hypertension: results from the COMPERA registry. Int J Cardiol 2013; 168: 871-880.

10 Humbert M, Khaltaev N, Bousquet J, et al. Pulmonary hypertension: from an orphan disease to a public health problem. Chest 2007; 132: 365-367.

11 D’Alonzo GE, Barst RJ, Ayres SM, et al. Survival in patients with primary pulmonary hypertension. Results from a national prospective registry. Ann Intern Med 1991; 115: 343-349.

12 Rich S, Dantzker DR, Ayres SM, et al. Primary pulmonary hypertension. A national prospective study. Ann Intern Med 1987; 107: 216-223.

13 Hoeper MM, Bogaard HJ, Condliffe R, et al. Definitions and diagnosis of pulmonary hypertension. J Am Coll Cardiol 2013; 62: Suppl., D42-D50.

14 Simonneau G, Gatzoulis MA, Adatia I, et al. Updated clinical classification of pulmonary hypertension. J Am Coll Cardiol 2013; 62: Suppl., D34-D41. 
15 Hughes JM, Pride NB. Examination of the carbon monoxide diffusing capacity $\left(\mathrm{DL}_{\mathrm{CO}}\right)$ in relation to its $\mathrm{KCO}$ and VA components. Am J Respir Crit Care Med 2012; 186: 132-139.

16 Allanore Y, Borderie D, Avouac J, et al. High N-terminal pro-brain natriuretic peptide levels and low diffusing capacity for carbon monoxide as independent predictors of the occurrence of precapillary pulmonary arterial hypertension in patients with systemic sclerosis. Arthritis Rheum 2008; 58: 284-291.

17 Montani D, Price LC, Dorfmuller P, et al. Pulmonary veno-occlusive disease. Eur Respir J 2009; 33: 189-200.

18 Cottin V, Le Pavec J, Prevot G, et al. Pulmonary hypertension in patients with combined pulmonary fibrosis and emphysema syndrome. Eur Respir J 2010; 35: 105-111.

19 Chandra S, Shah SJ, Thenappan T, et al. Carbon monoxide diffusing capacity and mortality in pulmonary arterial hypertension. J Heart Lung Transplant 2010; 29: 181-187.

20 Trip P, Nossent EJ, de Man FS, et al. Severely reduced diffusion capacity in idiopathic pulmonary arterial hypertension: patient characteristics and treatment responses. Eur Respir J 2013; 42: 1575-1585.

21 Trip P, Girerd B, Bogaard H-J, et al. Diffusion capacity and BMPR2 mutations in pulmonary arterial hypertension. Eur Respir J 2014; 43: 1195-1198.

22 Souza R, Amato MB, Demarzo SE, et al. Pulmonary capillary pressure in pulmonary hypertension. Crit Care 2005; 9: R132-R138. 